\title{
EVALUATION OF USING BUCCAL PAD OF FREE FAT TISSUE TRANSFER WITH IMMEDIATE IMPLANT PLACEMENT IN THE MAXILLARY POSTERIOR AREA (CLINICAL TRIAL)
}

\author{
Lobna A.Elwan ${ }^{1 *} B D S$, Nagy El prince ${ }^{2}$ PhD, Ahmed O. Sweedan ${ }^{3 P h D}$
}

\section{ABSTRACT}

INTRODUCTION: Implants placed immediately after tooth extraction; impose many challenges. One of them is the difference in size and form between the extraction socket and the simultaneously inserted implant. Soft tissue coverage of the implant area is considered substantial to attain bone filling adjacent to the implant.

OBJECTIVES: Evaluation of free tissue graft of buccal pad of fat (BPF) for primary soft tissue closure with immediately placed implants in the maxillary posterior region.

METHODS: Ten patients aged between 20 to 45 years were selected from the outpatient clinic of Alexandria University requesting a dental implant to replace an unrecoverable maxillary posterior tooth. One stage surgery including tooth extraction, placement of an immediate implant, bone grafting material and autologous soft tissue graft from the buccal pad of fat was carried out. Clinical and radiographical follow up were done for six months.

RESULTS: 10 patients (6 females and 4 males; mean age 34 years) were followed for 6 months .Soft tissue healing, was uneventful with only minor postoperative complications. Bone density and bone thickness measurements were significantly improved after 6 months from implant placement with full bone recovery around the implants compared with the 3months results.

CONCLUSION: Results of the study suggest that, the buccal pad of fat graft application is a new prospective modality for achieving primary soft tissue coverage over immediate implants.

KEYWORDS: immediate implants, buccal pad of fat, primary soft tissue coverage.

RUNNING TITLE: immediate implants with buccal pad of fat free graft.

1BDS, 2011, Faculty of Dentistry, Alexandria University, Egypt.

2Professor of Oral and Maxillofacial Surgery, Department of Oral and Maxillofacial Surgery Faculty of Dentistry, Alexandria University, Egypt.

3Lecturer of Oral and Maxillofacial Surgery, Department of Oral and Maxillofacial Surgery Faculty of Dentistry, Alexandria University, Egypt.

*Corresponding author:

E-mail: lobnaelwan@gmail.com

\section{INTRODUCTION}

Immediate implant insertion is described as implant placed immediately after tooth extraction, which most commonly needs to be combined with a bone graft to prevent peri-implant bone $\operatorname{loss}(1)$.

Placement of immediate implant after tooth extraction has many advantages as it reduces the treatment time and costs, preserves the gingival aesthetics by preventing atrophy of the alveolar ridge, and increases the comfort of the patient (2). The main advantage of immediate implant placement is the significant decrease of overall healing time between tooth extraction and prosthetic loading of the inserted implant. As the implant is placed at the time of extraction, osseointegration of the implant starts instantly with extraction site healing (3).

On the other hand, the main drawbacks of this technique are; the morphology of the site, ,the lack of keratinized tissue, a thin tissue biotype, the possible presence of periapical lesions and finally hard to achieve full soft tissue closure over the extraction socket (4), which subsequently will increase the risk of periimplantitis and decrease long-term implant survival rate(5).

The placement of immediate implants in the maxillary posterior area is challenging for soft tissue healing and osseointegration because of the wide soft and hard tissue gaps presented after tooth extraction (6).

Current literature suggests the periimplant extraction socket to be grafted and to recover the soft tissue defect by biomaterials or soft tissue grafts (7).

Primary flap closure over immediate implants was recommended to be important for many years (8). Various soft tissue procedures can be used to cover the extraction site and to 
gain primary closure of the bone-augmented socket, which include autogenous and non-autogenous soft tissue grafts, periostal releasing cuts at the flap, rotated buccal flap, palatal advanced flap, rotated split palatal flap and back cut techniques (9-11).

For example rotated buccal flap can be used with membrane barriers or grafting material, but the sufficient width of keratinized mucosa and vestibular depth are the most common drawbacks of this technique.

Connective tissue graft also can be used for the immediate implant soft tissue coverage, but its disadvantage is the limited size of donor tissue.

The palatal advanced flap or pedicle flap is another option for maxillary immediate implants, but the main drawback is the extended and inconvenient secondary palatal tissue healing. Acellular dermal matrix allografts also can be used (12). To overcome the drawbacks of these grafting techniques, the buccal pad of fat tissue can be used with many advantages.

One of the published modalities to achieve initial soft tissue coverage over the bone augmented sites is using buccal pad of free fat tissue graft (BPF) (13).

The buccal pad of fat has been used widely in oral and maxillofacial surgery for maxillary defects, such as defects of the alveolar crest in the retromolar region of the mandible and maxilla, the vestibular sulcus, hard and soft tissue palate cleft, and closing oroantral communication (14).

Many benefits of using BPF in oral reconstruction are described in the literature such as: fast and simple procedure, surgery can be performed in local anesthesia, no facial asymmetry results from the elevation of the flap, no apparent scars are left, and failure rates are rare (15).

It was documented that using BPF graft over the bone graft promotes primary soft tissue closure, avoids exposure of bone graft to the oral cavity and increases soft tissue recovery and simulates the fibrous healing of the attached gingiva (7).

The purpose of this study was to evaluate the benefits of using buccal pad of fat tissue graft with immediately placed implants in the maxillary posterior area.

\section{MATERIALS AND METHODS}

This study was completed in agreement with Ethic research board, Faculty of Dentistry, Alexandria University \# 003206/2019. This clinical trial was registered at clinicalTrials.gov \# NCT04415619

Study design: The study strategy was established as a clinical evaluation study.

Study sample: This clinical study was performed at the inpatient clinic of the oral and Maxillofacial Surgery Department, Faculty of Dentistry, Alexandria University. It comprised of 10 patients with prosthetically and surgically unrecoverable maxillary posterior tooth (premolar and molar). All patients were aware of the objectives of the designed study and a written consent was acquired.

Sample size estimation: A minimal total sample size of 10 patients was selected from the outpatient clinic, Faculty of Dentistry, Alexandria University.

\section{Eligibility criteria:}

I. Age of patients is between 20-45 years with no gender predilection.

II. Patients with non-restorable maxillary posterior tooth which need to be extracted (premolar -molar region).

III. Patients with good oral hygiene.

IV. Bony defects more than $2 \mathrm{~mm}$ during implant placement to be treated by bone substitute.

V. Patients fully capable to comply with the study protocol.

Omission criteria:

I. Patients with any systemic disease affecting bone quality as uncontrolled diabetes.

II. Heavy smokers (more than 20 cigarettes per day).

III. Sites with acute oral infection.

IV. Pregnant and lactating women.

V. Untreated periodontal disease.

VI. Previous chemotherapy or head and neck irradiation.

VII. Inadequate interocclusal space.

\section{Materials used:}

1. Implant (Superline ${ }^{\circledR}$, Dentium $\mathrm{Co}^{\mathrm{TM}}$ ).

2. Osstell (ISQ $\left.{ }^{\circledR}\right)$.

3. Xenograft bone substitute (Osteo-biol).

Implant; The superline implant system (Superline,DentuimCo ${ }^{\mathrm{TM}}$,Doublethread,S.L.A surface ,Korea.) with different diameters (3.6, $4.0,4.4,4.9$, 6.0 ,7.0 mm) and different lengths $(7,8,10,12,14 \mathrm{~mm})$ was used in this study.

Osstell; (Qsstel, Austeria). Resonance frequency analyzer (RFA) consists of Osstell ISQ instrument, SmartPeg , charger, USB cable, and probe. The system includes using of a SmartPeg ${ }^{\mathrm{TM}}$ connected to the dental implant by an integrated screw. The SmartPeg is excited by a magnetic pulse from the measurement probe on the handheld instrument. The resonance frequency is calculated from the response signal. Implant stability measurements are displayed on the instrument as the implant stability quotient (ISQ), which is scaled from 1 to 100 . The higher the number of ISQ, the more stable the implant is.

Xenograft bone substitute; Osteo-biol Gen-oss ( Tecnos ${ }^{\circledR}$,Italy.) bone substitute was used in this study which is heterologous Cortico-cancellous porcine bone mix, with granules size $250-1000 \mu \mathrm{m}$.it was mixed with either a few drops of sterile physiological solution (or patient's blood) to activate its collagen matrix and to enhance its adhesivity.

\section{Pre-operative assessment and examination:}

Detailed personal history, past medical history, past dental history and chief complaint were taken for each patient.

\section{Clinical examination}

Clinical examination of buccal and palatal soft tissue sides of the tooth to be extracted and replaced by implant and periodontal evaluation includes periodontal disease, gingival recession and bone defects were assessed for all patients. (Figure 1) 


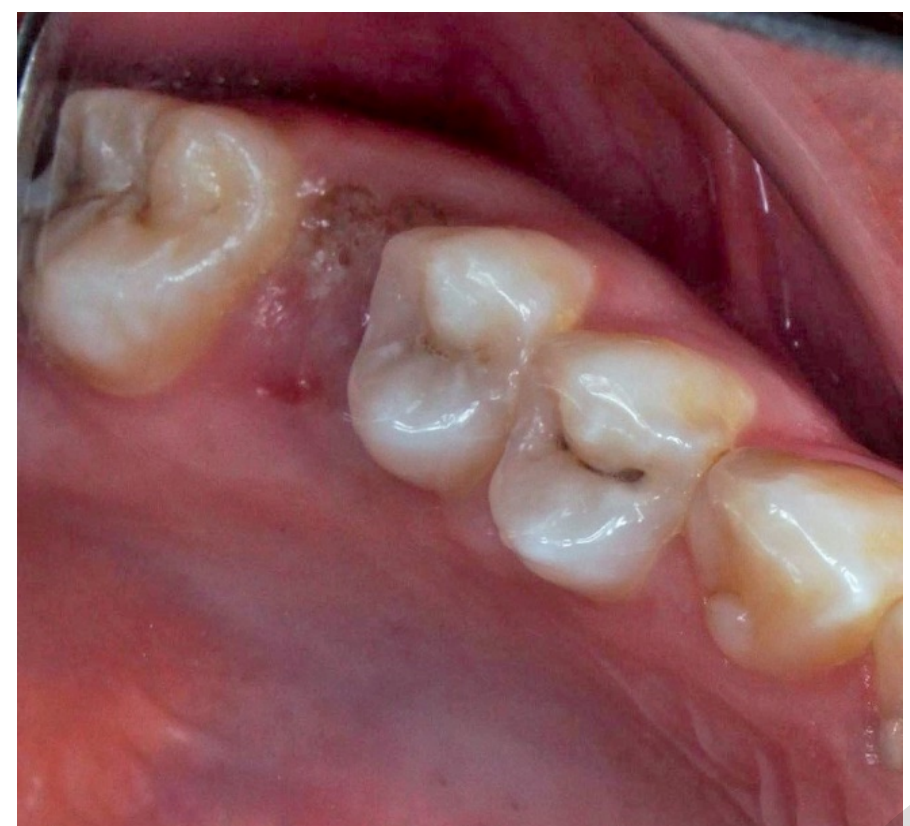

Figure (1): preoperative clinical view showing non-restorable maxillary first molar

\section{Radiographic examination}

All patients performed panoramic x-rays before surgery for initial examination and to ensure absence of any periapical pathology then a CBCT to evaluate the relation with surrounding anatomical structures. (Figure 2)

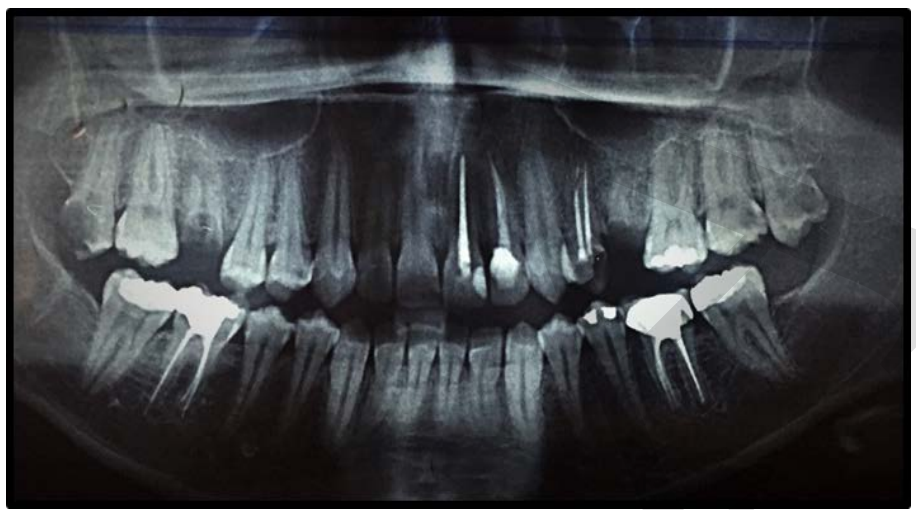

Figure (2); preoperative panoramic x-ray showing maxillary right first molar remaining roots

\section{Presurgical preparation:}

Patients were guided to use chlorhexidine antiseptic mouth wash for 2 minutes before surgery then application of local anesthesia was done using $4 \%$ articaine (1:100,000 adrenaline).(Articaine 4\%: Alexandria Co. for pharmaceuticals chemical industries.)

Surgical phase (16)

First atraumatic maxillary posterior tooth extraction was done using an extraction forceps, then sulcular excision was made around the extraction site .One or two releasing incisions was done then a mucoperiosteal flap was elevated.
Next step was implant bed preparation and drilling according to the manufacturer's guidelines.

Adequate primary stability of the immediately placed implant was measured using Osstell ISQ ${ }^{\circledR}$ then the xenograft bone substitute was placed in the gap around the implant to cover the bone defect after extraction.

Under local anesthesia, the BPF was accessed via horizontal incision of the periosteum, posterior to the zygomatic buttress area, near to the second molar tooth and expanding antroposteriorly.

Blunt dissection was used to access and mobilize the free graft from its bed, the free fat graft was customized to the size of the recipient site, and placed over the soft tissue defected area and secured with 4/0 vicryl sutures as following;

- Four horizontal mattress sutures at the flap corners, 2 at the buccal side (mesial and distal) and 2 at the palatal side (mesial and distal).

- Then interrupted sutures that pass through the free fat graft from buccal side to the palatal side until the final closure of the flap is done. (Figure 3\&4).

- After 7 days from surgery, sutures were removed.

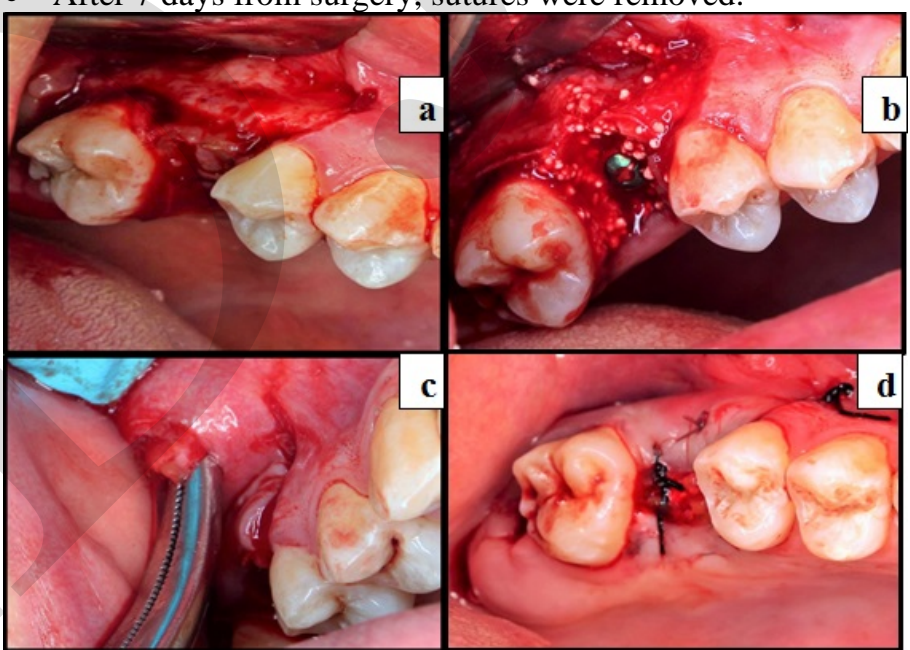

Figure (3); The surgical procedure

a) Elevation of mucoperiosteal flap.

b) Tooth extraction and implant placement with bone graft.

c) Blunt dissection to reach and mobilize the buccal pad of fat.

d) Suturing of the BPF over the immediate implant.

\section{Post-operative care and follow up}

Post-operative care\& medications:

Patients were given comprehensive oral hygiene care and postoperative instructions, including; soft diet, cold fomentation extraorally immediately after the surgery, avoid suction by drinking straws, nose blowing trauma, hot drinks and smoking. They were advised to take the prescribed medications, which include:

- Amoxicillin 875mg +Clavulanic acid 125mg (Augmentin: GalaxoSmithKline,UK.) every 12 hours for 7 days.

- Non Steroidal Anti Inflammatory drugs (Cataflam: Diclofenac potassium 50mg: Novartis. Switzerland.) Every 8 hours for 4 days.

- Chymotrypsin+Trypsin 300E.A.U(Alphintern: 
Chemotrypsin 300 E.A.U (14microkatals) +Trypsin 300 E.A.U (5microkatals): Amoun Pharmaceutical Co. S.A.E.) every 8 hours for 5 days

- $0.12 \%$ chlorhexidine mouth rinse (Hixetol: Chlorhexidene 125mg/100ml concentration 0.125\%: Arabic drug company, ADCO.) 3 times daily for 2 weeks.

\section{Postoperative Evaluation}

\section{Postoperative pain and swelling:}

The visual analog scale (VAS) a 10 -point from 0 to 10 (0 means no pain, 10 is severe pain) was utilized to gauge the degree of post-operative pain at $2 \mathrm{hr}, 6 \mathrm{hr}, 12 \mathrm{hr}$ postoperatively and daily for the 7 days after the operation.

And for swelling: a 10-point scale of four parameters was used; none (0 -2.5) (absence of swelling), light (2.6 -5) (localized to the treated area, intraorally), moderate (5.1 -7.5) (swelling localized to the treated area, extraorally), and severe (7.6 -10) (swelling expanding beyond the treated area, extraorally).

\section{Evaluation of soft tissue healing;}

Patients were followed up after 1week, 4weeks and 4 months for the Presence/absence of postoperative complications, including:

Hematoma, wound dehiscence, bleeding, partial flap necrosis, local infection, excessive granulation tissue, edema, facial asymmetry and mouth opening limitation.

3. Implant stability

It was measured by implant stability meter $\left(\right.$ Osstell ${ }^{\mathrm{TM}}$ ) immediately postoperative and after 6 months.

\section{Radiographic evaluation (figure 6)}

Cone beam computed tomography (CBCT) software "On Demand 3D App” after 3 and 6 months of implant placement to assess;

i. Bone density.

ii. Amount of bone formation buccal and palatal to the implant.

iii. Marginal bone level.

\section{Measurement of bone density:}

On demand 3D APP* was used to evaluate radiographic bone density buccal, palatal and apical to each implant as following

1. From the area of selection tools on the bar, the rectangular selection tool was used to specify the area. (ROI)

2. Defining the area buccal, palatal and apical to the implant then a range of density for each area was determined.

Measurement of the amount of bone buccal and palatal to the implant:

Using the same On demand 3D APP software; from the area of selection tools on the bar, the ruler tool was used to measure the length and width of bone from fixed points buccal and palatal to each implant.

Measurement of the marginal bone level:

Using the same software app, the ruler tool was selected and measuring from the margin of the inner aspect of basal bone buccal and palatal to the margin of each implant.

\section{Statistical Analysis of the data}

All of the obtained data was analyzed statistically and presented in the form of charts, graphs and tables using the IBM SPSS (statistical package for social science) software version 22.0.

Quantitative data was styled using mean, median, range (minimum and maximum), and standard deviation.

The used tests were:

1. Friedman test

2. Paired t-test

3. Wilcoxon signed ranks test

\section{RESULTS}

An overall of ten patients (six females and four males), with age ranging from 22 and 43 years (with mean \pm standard deviation; $33.80 \pm 7.98)$ joined this study.

\section{Clinical outcomes}

\section{Pain}

Mean values of the VAS scores for the ten patients at $2 \mathrm{hr}$, $6 \mathrm{hr}$ were $3.6 \pm 2.4 \mathrm{~mm}$ and $3.8 \pm 1.0 \mathrm{~mm}$.

Mean values of the VAS scores from the $1^{\text {st }}$ to the $7^{\text {th }}$ days were $4.1 \pm 1.7 \mathrm{~mm}, 3.3 \pm 1.8 \mathrm{~mm}, 2.8 \pm 1.6 \mathrm{~mm}, 1.9 \pm 1.4 \mathrm{~mm}, 0.7 \pm$ $1.1,0.0 \pm 0.0 \mathrm{~mm}$ and $0.0 \pm 0.0 \mathrm{~mm}$.

These results show slight pain on the first postsurgical day, which gradually decreased until it completely subsided in all patients after 5 days. (Figure 5)

Figure (5): Line chart Showing Comparison between the different periods according to postoperative pain (VAS) $(n=10)$ Edema

According to the results, most of the cases suffered from moderate facial swelling in the first 4 days then started to decrease gradually from the $5^{\text {th }}$ day of operation. (Table 1 )

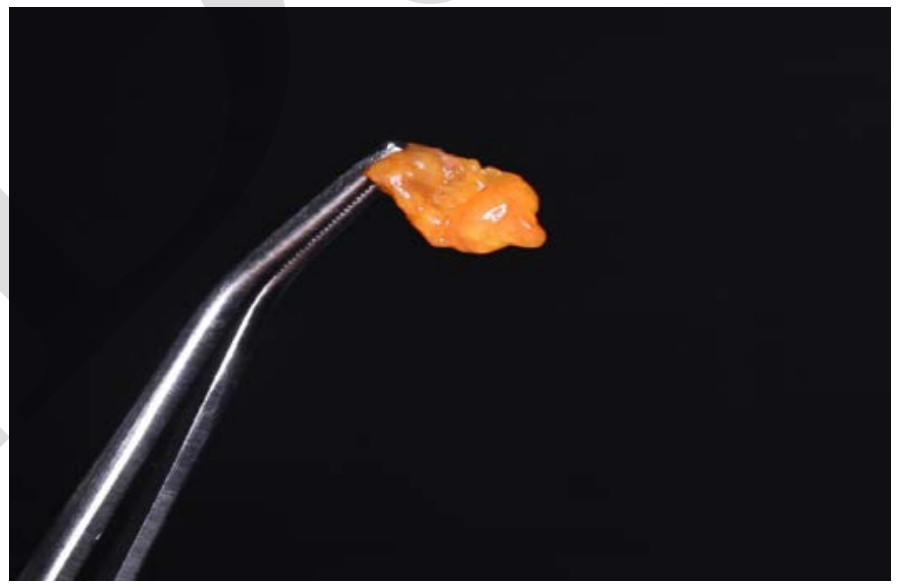

Figure (4): The harvested buccal pad of fat tissue

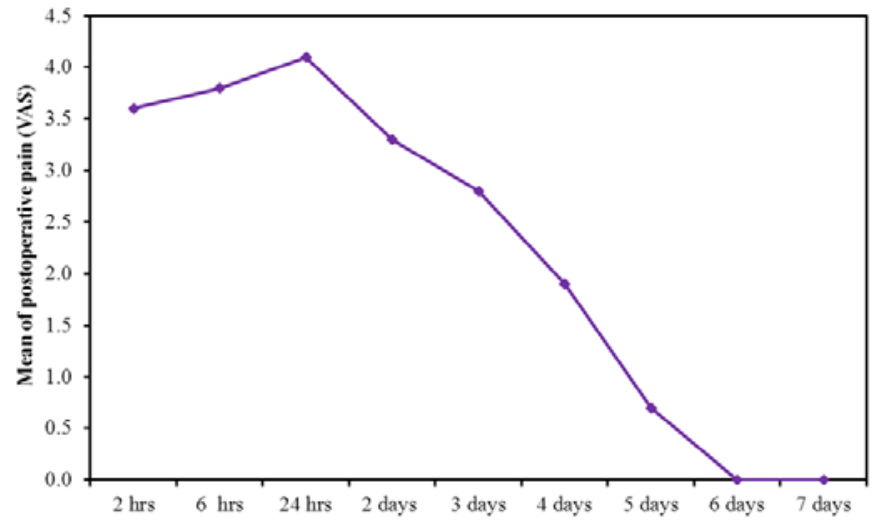

Figure (5): Line chart Showing Comparison between the different periods according to postoperative pain (VAS) $(n=10$ 


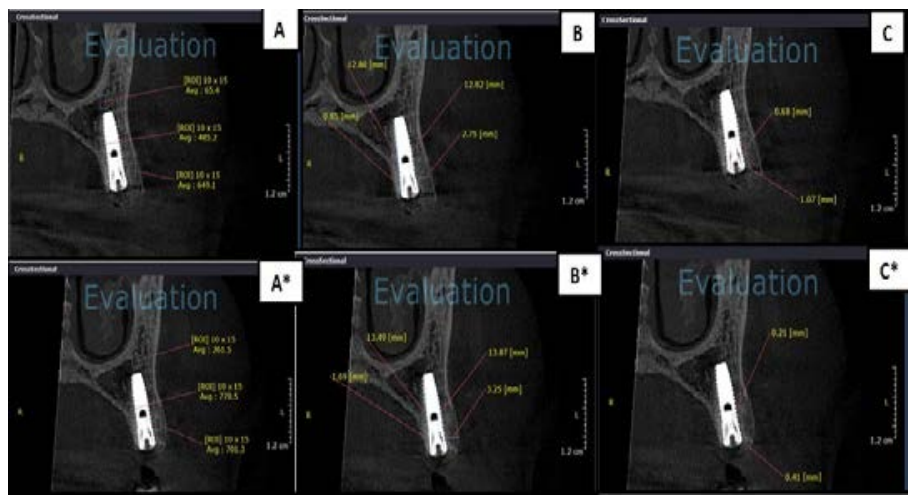

Figure (6): A,B,C (bone density,amount of bone formation buccal and palatal,marginal bone level) at 3 months

$A^{*}, B^{*}, C^{*}$ (bone density,amount of bone formation buccal and palatal,marginal bone level) after 6 months

Table (1): Comparison between the different periods according to postoperative swelling $(\mathrm{n}=10)$

\begin{tabular}{|c|c|c|c|c|c|c|c|c|c|c|c|c|c|c|c|c|c|c|c|}
\hline & \multicolumn{17}{|c|}{ Postoperative swelling } & \multirow{3}{*}{ Fr } & \multirow{3}{*}{ 仡 } \\
\hline & \multicolumn{2}{|c|}{2 hrs } & 6 hrs & \multicolumn{2}{|c|}{24 hrs } & \multicolumn{2}{|c|}{2 days } & \multicolumn{2}{|c|}{3 days } & \multicolumn{2}{|c|}{ 4 days } & \multicolumn{2}{|c|}{5 days } & \multicolumn{2}{|c|}{6 days } & \multicolumn{2}{|c|}{7 days } & & \\
\hline & No. & $\%$ & \begin{tabular}{l|l} 
No. & $\%$ \\
\end{tabular} & No. & $\%$ & No. & $\%$ & No & $\%$ & No & $\%$ & No & $\%$ & No & $\%$ & No & $\%$ & & \\
\hline None & 2 & 20.0 & \begin{tabular}{l|l}
1 & 10.0
\end{tabular} & 0 & 0.0 & 0 & \begin{tabular}{|l|}
0.0 \\
\end{tabular} & 0 & 0.0 & 0 & 0.0 & 10 & 100 & 10 & 100 & 10 & 100 & & \\
\hline Light & 3 & 30.0 & 110.0 & 2 & 20.0 & 5 & 50.0 & 6 & 60.0 & 1 & 100 & 0 & $\mid 0.0$ & 0 & 0.0 & 0 & 0.0 & & \\
\hline Moderate & 2 & 50.0 & $\begin{array}{lll}4 & 40.0\end{array}$ & 3 & 30.0 & 4 & 40.0 & 4 & 40.0 & 0 & 0.0 & 0 & $|0|$ & 0 & 0.0 & 0 & 0.0 & $63.02^{*}$ & $<0.001$ \\
\hline Severe & $\mathbf{0}$ & 0.0 & $\begin{array}{lll}4 & 40.0\end{array}$ & 5 & 50.0 & 1 & 10.0 & 0 & 0.0 & 0 & 0.0 & 0 & 0.0 & 0 & 0.0 & 0 & 0.0 & & \\
\hline $\mathbf{p}_{1}$ & & & 0.178 & & 079 & & 624 & & .838 & & 624 & & $003^{*}$ & & $03^{*}$ & & $03^{*}$ & & \\
\hline
\end{tabular}

Fr: Friedman test, Sig. bet. periods was done using Post Hoc Test (Dunn's)

$\mathrm{p}$ : $\mathrm{p}$ value for comparing between the studied periods

$\mathrm{p}_{1}$ : $\mathrm{p}$ value for comparing between $2 \mathrm{hrs}$ and each other period

*: Statistically significant at $\mathrm{p} \leq 0.05$

\section{Soft tissue healing}

Healing of BPF showed a very good outcome; absence of bleeding, hematoma, dehiscence, partial flap necrosis, excessive granulation tissue and facial asymmetry except for 2 patients who suffered from local infection with edema and subsequently trismus and were managed by proper antibiotic prescription and corticosteroids with hot fomentation and muscle relaxant then follow up.

In all patients epithelization of the BPF graft was completed 4 weeks after surgery, then after 4 months; the soft tissue over the implant site showed clinically smooth healthy looking gingiva which indicated fibrotic healing of the graft.

\section{Implant stability}

Using osstell, immediately after implant placement, the measurements revealed very good stability in all implants. The implant stability quotient (ISQ) ranges of readings were between52.0 - 90.0. The median records were 68.0 (61.0 - 75.0) and the mean $\pm \mathrm{SD}(69.3 \pm 11.0)$.

After 6 months, the measurements were taken for all the implants. All implants showed increase in ISQ value ranging between55.0 - 90.0. The median records were $75.0(70.0-86.0)$ and the mean \pm SD $(75.4 \pm 12.20)$. (Table 2)
Table (2): Comparison between the two periods according to Measurement of implant stability (Osstell ISQ) $(\mathrm{n}=10)$

\begin{tabular}{|c|c|c|l|l||}
\hline $\begin{array}{l}\text { Measurement of } \\
\text { implant stability } \\
\text { (Osstell ISQ) }\end{array}$ & Immediately & After 6 months & T & p \\
\hline Min. - Max. & $52.0-90.0$ & $55.0-90.0$ & & \\
Mean \pm SD. & $69.3 \pm 11.0$ & $75.4 \pm 12.20$ & $3.556^{*}$ & $0^{0006}$ \\
Median (IQR) & $\mathbf{6 8 . 0}(61.0-75.0)$ & $75.0(70.0-86.0)$ & & \\
\hline
\end{tabular}

t: Paired t-test

$\mathrm{p}$ : $\mathrm{p}$ value for comparing between the studied periods

*: Statistically significant at $\mathrm{p} \leq 0.05$

\section{Radiographic evaluation}

According to the CBCT measured data at 3 months and after 6 months from implant placement procedure; the mean value of the peri-implant bone density was $635.8 \pm 251.8 \mathrm{HU}$ after three months then after six months; the mean value of the periimplant bone density was $849.9 \pm 239.4 \mathrm{HU}$ which indicates a significant increase in the bone density for the ten implants.

According to the amount of bone formation buccal and palatal to the immediately placed implants, after 3 months from bone graft placement, the mean vertical bone located buccally was $(12.07 \pm 0.99 \mathrm{~mm})$ and palatally was $(12.12 \pm 0.88 \mathrm{~mm})$ and the mean of bone thickness (horizontal) bucally was (2.90 \pm 0.85 $\mathrm{mm})$ and palatally was $(2.37 \pm 0.96 \mathrm{~mm})$.

After 6 months postoperatively, the mean vertical bone formed buccally was $(12.55 \pm 1.14 \mathrm{~mm})$ and palatally was $(12.70 \pm 0.83$ $\mathrm{mm}$ ) and the mean of bone thickness (horizontal) formed bucally was $(3.52 \pm 0.75 \mathrm{~mm})$ and palatally was $(3.13 \pm 0.98 \mathrm{~mm})$.

These results indicate a significant increase in the amount of bone formed buccal and palatal after 6 months from implant placement compared to the 3 months results.

Concerning the marginal bone level measurements at 3 months, the mean value of marginal bone level buccally was (1.13 \pm $0.68 \mathrm{~mm})$ and palatally was $(0.96 \pm 0.83 \mathrm{~mm})$.

After 6 months postoperatively, the mean value of marginal bone level buccally was $0.51 \pm 0.34 \mathrm{~mm}$ and palatally was 0.51 $\pm 0.60 \mathrm{~mm}$.

These results showed a significant decrease in marginal bone level after 6 months compared to the 3 months results, both buccal and palatal to the immediately placed implants in all cases. (Table 3)

Table (3): Comparison between the different periods according to marginal bone level of radiographic evaluation

\begin{tabular}{|c|c|c|c|c|}
\hline $\begin{array}{l}\text { Marginal } \\
\text { bone level }\end{array}$ & At 3 months & After 6 months & $\mathbf{Z}$ & $\mathbf{p}$ \\
\hline $\begin{array}{l}\text { Buccal } \\
\text { Min. - Max. } \\
\text { Mean } \pm \text { SD. } \\
\text { Median (IQR) }\end{array}$ & $\begin{array}{l}0.30-2.26 \\
1.13 \pm 0.68 \\
1.0(0.43-1.70)\end{array}$ & $\begin{array}{l}0.14-1.25 \\
0.51 \pm 0.34 \\
0.47(0.21-0.60)\end{array}$ & $2.803^{*}$ & $0.005^{*}$ \\
\hline $\begin{array}{l}\text { Palatal } \\
\text { Min. - Max. } \\
\text { Mean } \pm \text { SD. } \\
\text { Median (IQR) }\end{array}$ & $\begin{array}{c}0.21-2.59 \\
0.96 \pm 0.83 \\
.67(0.52-0.90)\end{array}$ & \begin{tabular}{|c}
$0.11-1.69$ \\
$0.51 \pm 0.60$ \\
$0.23(0.21-0.31)$
\end{tabular} & $2.805^{*}$ & $0.005^{*}$ \\
\hline
\end{tabular}

Z: Wilcoxon signed ranks test

$\mathrm{p}$ : $\mathrm{p}$ value for comparing between the studied periods

*: Statistically significant at $\mathrm{p} \leq 0.05$ 


\section{DISCUSSION}

This clinical study presents the free fat graft tissue of buccal pad as a new soft tissue graft for primary soft tissue closure over immediately placed implants. The final clinical and radiographic outcomes were satisfactory and the surgical technique was fast and easy.

According to the surgical protocol used in this study, we used the buccal pad of fat as a new soft tissue graft which has been used widely in the oral and maxillofacial reconstruction and many applications were documented. Singh et al. reviewed its uses in oral and maxillofacial reconstruction and its possible advantages and disadvantages, with special respect to its size and applications for the posterior areas of the oral cavity (17).

In this study we experienced many advantages during the surgical procedure which were; the buccal pad of fat is easily accessed through the oral cavity, plenty of fat tissue can be used if needed, the free graft is easily spread over the soft tissue defect, the free fat tissue could be left exposed partially to the oral cavity with tension free sutures and finally fibrotic healing of the graft provides a good seal over the immediately placed implants with thick healthy soft tissue .This corresponds to the studies of Kablan who used the buccal pad of fat in his studies as a soft tissue graft over the bone augmented sites with good results and no complications $(11,13)$.

In this study, we placed 10 implants immediately in the fresh extractions sockets in posterior maxilla with bone grafting and buccal pad of fat soft tissue graft as one procedure with no need for a second surgery as in Kablan study (13) who made his study as 2 stages procedure, first is the soft tissue augmentation and the second one is the implant placement.

Regarding the postoperative pain and swelling, highest scores of pain levels (VAS) was in the first day postoperatively then gradual relief of pain took place and for the edema most of the cases suffered from moderate facial swelling in the first 3 days then started to decrease from the $4^{\text {th }}$ day of operation.

In the present study, all patients had a good soft tissue healing; this was harmonious with Kablan study (13), except for 2 patients who presented with local infection in the surgical site which may be due to improper commitment to the postoperative instructions and medications.

As for implant stability, it was measured by ossstell immediately postoperatively and after 6 months .results showed good readings for the primary stability and a significant increase in the secondary stability which includes primary healing process around the dental implant, and it's determined by primary stability process of osseointegration which developed from remodeling and regeneration of the bone and tissue around the inserted dental implants, this in agreement with Pierre Layrolle study which emphasize the relevance for primary stability of cortical thickness around dental implants (18).

Using cone beam computed tomography (CBCT) software "On Demand 3D App" after 3 months and after 6 months of implant placement to evaluate bone density around the implant; it showed gradual increasing after 3 months from implant placement till 6 month postoperatively. This increase was due to healing ability of the bone and construction of new bone inside the extraction sockets and around the implants. The increase in peri-implant bone density indicates osseointegration of all implants. That was compatible with Han and Park, when confirmed that by time there calcified tissue around implant surface (19).

Regarding the amount of bone formed vertically and horizontally buccal and palatal to the implant, it was clear that there was a marked increase in the amount of bone formed at 3 months and 6 months follow up which enhance the advantage of immediate implant placement by prevention the dimensional changes of bone occurring after tooth extraction with minimizing the buccal and palatal gaps around the implant these findings corroborate the results of Mariano Sanz who explained that extraction of a single tooth and immediate implant placement caused remarkable changes of the dimension of the buccal ridge (43\% and 30\%) and the horizontal gap (80$63 \%$ ) as well as the vertical (69-65\%) between the implant and the bone walls (20).

In this study, we evaluated the marginal bone level after 6 months follow up and there was a significant decrease in compared to 3 months data. This in accordance with SuarezLopez who mentioned that the thicker the peri-implant soft tissue was found to be favoring better marginal bone preservation when compared to a thinner tissue, this explains the good results of MBL reduction in our study (21).

Therefore, the outcome of this study confirmed the hypothesis that immediately placed implants reduced alveolar bone resorption.

\section{CONCLUSIONS}

It was concluded from the results of this study that:

1. Buccal pad of fad free tissue graft is new prospective modality for achieving primary soft tissue coverage over immediate implants.

2. Immediately placed implant is a successful treatment choice for replacement of hopeless tooth.

\section{CONFLICT OF INTEREST}

The authors declare that they have no conflicts of interest.

\section{REFERENCES}

1. Glossary Of Oral And Maxillofacial Implants. Quintessence PublishingCo., 2007.

2. Singh M, Kumar L, Anwar M, Chand P. Immediate dental implant placement with immediate loading following extraction of natural teeth. Natl J Maxillofac Surg 2015;6:252-5.

3. Newman MG, Takei HH, Klokkevold PR, Carranza FA. Clini Periodontol. Saunders. Copyright 2006.

4. Chen ST, Wilson TG Jr, Hammerle CH. Immediate or early placement of im-plants following tooth extraction: Review of biologic basis, clinical procedures, and out-comes. Int J Oral Maxillofac Implants 2004;19 Suppl: 12-25 
5. Poskevicius L, Sidlauskas A, Galindo-Moreno P, Juodzbalys G. Dimensional soft tissue changes following soft tissue grafting in conjunction with implant placement or around present dental implants: A systematic review. Clin Oral Implants Res. 2017;28(1):1-8

6. Covani U, Cornelini R, Barone A. Bucco-lingual bone remodeling around implants placed into immediate extraction sockets: A case series. J Periodontol. 2003; 74 (2):268-73.

7. Garcia JJ, Sanguino D. A new protocol for immediate implant: the rule of 5 triangles: a case report. EAO .2014 Dec; 21:4-5.

8. Goldstein M, Boyan BD, Schwartz Z. The palatal advanced flap: a pedicle flap for primary coverage of immediately placed implants. Clin Oral Implants Res 2002: 13: 644-650

9. Batista EL., et al. "Management of soft tissue ridge deformities with acellular dermal matrix, Clinical approach and outcome after 6 months of treatment”. Journal of Periodontology 72.2 (2001): 265-273.

10. Nemcovsky CE, Artzi Z, Moses O. Clinical Coverage of Dehiscence Defects in Immediate Implant Procedures: Three Surgical Modalities to Achieve Primary Soft Tissue Closure.INT J ORAL MAXILLOFAC IMPLANTS 2000; 15:843-852.

11. Fares Kablan., et al. Back Cut: A Novel Technique for Primary Soft Tissue Closure Over Particulate BoneAugmented Extraction Sites. EC Dental Science 6.2 (2016): 1281-1287.

12. Becker W, MosheG. Immediate Implant Placement: Treatment planning and surgical steps for successful outcome. Periodontology. 2000; 47:79-89.

13. Kablan F , Laster Z. The use of free fat tissue transfer from the buccal fat pad to obtain and maintain primary closure and to improve soft tissue thickness at bone-augmented sites: Technique presentation and report of case series. International Journal of Oral \& Maxillofacial Implants 29.2 (2014): e220-e231.

14. Baumann A, Ewers R .Application of the buccal fat pad in oral reconstruction. J Oral Maxilofac Surg 2000; 58:389392.

15. Dean A, Alamillos F, Garcia-Lopez A, Sanchez J, Penalba $M$.The buccal fat pad flap in oral reconstruction. Head Neck 2001; 23:383-388.
16. Peñarrocha-Diago M, Alonso-González R, Aloy-Prósper A, Peñarrocha-Oltra D, Camacho F, Peñarrocha-Diago M. Use of buccal fat pad to repair post-extraction peri-implant bone defects in the posterior maxilla. A preliminary prospective study. Med Oral Patol Oral Cir Bucal. 2015 Nov; 20(6): e699-706.

17. Singh J, Prasad K, Lalitha RM, Ranganath K. Buccal pad of fat and its applications in oral and maxillofacial surgery: A review of published literature (February) 2004 to (July) 2009. Oral Surg Oral Med Oral Pathol Oral Radiol Endod 2010; 110:698-705.

18. Rozé J, Babu S, Saffarzadeh A, Gayet-Delacroix M, Hoornaert A, Layrolle P. Correlating implant stability to bone structure. Clin Oral Implants Res. 2009 Oct; 20(10):1140-5.

19. Hn TJ, Park KB. Surgical aspect of dental implants. In: Newman MG, Takei HH, Carranza FA (eds). Carranza's clinical periodontology. 9th ed. Philadelphia: WB Saunders; 2002. p.898.

20. Sanz M, Cecchinato D, Ferrus J, Pjetursson EB, Lang NP, Jan L. A prospective, randomized-controlled clinical trial to evaluate bone preservation using implants with different geometry placed into extraction sockets in the maxilla. Clin. Oral Impl. Res. 21, 2010; 13-21.

21. Suarez-Lopez Del Amo F, Lin GH, Monje A, GalindoMoreno P, Wang HL. Influence of soft tissue thickness on peri-implant marginal bone loss: A systematic review and meta-analysis. J Periodontol. 2016; 87(6):690-9. 